\title{
The application of multiwalled carbon nanotubes as solid phase extraction sorbent for pre- concentration of bisphenol a in canned food
}

\begin{abstract}
A simple, reliable and suitable analytical method was developed for solid phase extraction of bisphenol A in several canned food products such as beverages, fruits, vegetables and foodstuffs bought in Sudan markets. The analysis done by using a packed Multi Walled Carbon Nanotubes (MWNTs) mini-column followed by high-performance liquid chromatography with fluorescence detection. In summary, we have preliminarily demonstrated that as promising sorbents, MWNTs have great potential for solid phase extraction of BPA. The recommended parameters of proposed method influencing the preconcentration of the analytes, such as $\mathrm{pH}$ of the sample, flow rate and sample volume have been used. Under the optimized conditions, the calibration graphs were linear with the correlation coefficient ranged 0.9906-0.9999. According to the results, the concentrations of BPA in samples exposed to direct sunlight were higher than samples that stored at room temperature. The range of BPA level of beverages were $(0.3-0.8 \mathrm{ng} / \mathrm{ml})$ at room temperature where it were $(1.5-2.1 \mathrm{ng} / \mathrm{mL})$ at beverages exposed to direct sunlight, in vegetables the levels were (20.0-38.0ng/g) at room temperature and (30.0-43.0ng/g) in vegetables exposed to direct sunlight, the levels in fruits were $(6.0-24.0 \mathrm{ng} / \mathrm{g})$ at room temperature and in fruits exposed to direct sunlight were $(8.0-38.0 \mathrm{ng} / \mathrm{g})$, in fat-containing products the levels of BPA at room temperature were $(2.1-45.0 \mathrm{ng} / \mathrm{g})$ and $(3.0-55.0 \mathrm{ng} / \mathrm{g})$ in products which exposed to direct sunlight. Limits of detection $(\mathrm{S} / \mathrm{N}=3)$ from $0.1 \mathrm{ng} / \mathrm{mL}$ in beverages to $5.5 \mathrm{ng} / \mathrm{g}$ in fruits. The accuracy of proposed method was tested by recovery measurements on standard bisphenol A spiked canned food samples, the recoveries ranged $90.2-102.0 \%$ were obtained.
\end{abstract}

Keywords: bisphenol a, canned food, multiwalled carbon nanotubes, solid phase extraction, high performance liquid chromatography, florescence detector
Volume 5 Issue 5 - 2017

\section{Leena Omer, Abdalla Ahmed Elbashir, Hassan El obid Ahmed}

Department of Chemistry, Faculty of science, University of Khartoum, Sudan

Correspondence: Abdalla Ahmed Elbashir, Department of Chemistry, Faculty of science, University of Khartoum, Sudan, Email aaelbashir@uofk.edu

Received: January 30, 2017 | Published: July 25, 2017
Abbreviations: BPA, bisphenol A; GC, gas chromatography; HPLC, high-performance liquid chromatography; SPE, solid phase extraction; CNTs, carbon nanotubes; MWCNTs, multi walled carbon nanotubes; LODs, limit of detections

\section{Introduction}

The most effective method for the preservation of food from heat or chemical treatment is through sealing of food in tight containers. ${ }^{1,2}$ Different types of food such as fish, meat, fruits and vegetable can be stored safely in airtight sealed containers. ${ }^{3-5}$ In general the process of canned foods involve washing, cutting and filling in metal containers a long with a canning fluid such as water, salted water or fruit juice. Bisphenol A (2,2-bis(4-hydroxyphenyl)propane) (BPA) is a toxic chemical used essentially as a monomer or starting material in the production of cans, epoxy resin and polycarbonate bottles. BPA can leach into foods from the lacquer lining of cans and from other food containers and bottles made from certain plastic.BPA is an endocrine disruptor meaning that it's a chemical that can interfere with the endocrine (or hormonal system). Endocrine disruptors can cause cancerous tumors, birth defects and other developmental disorders. BPA was shown to be associated with breast and prostate cancers, genital defects in males.$^{6-8}$ Due to possible low dose effects of unknown toxicological relevance and weekly oestrogenic BPA is the subject of many investigating assessing, its potential toxicity and human exposure for a more conclusive risk assessment. ${ }^{9,10}$ Nowadays the exposure of human to BPA is estimated to be mainly by food consumption and widely spread, while air, dust and water. BPA in food and beverages accounts of the majority of daily human exposure.
Chromatographic techniques such as GC or HPLC are among the most widely used methods for analysis of harmful organic contaminants such as BPA. ${ }^{11-13}$ However their sensitivity and selectivity are usually insufficient for direct determination of these contaminants at very low concentration level in complex matrix food samples. Therefore, a sample extraction and clean up prior to chromatographic analysis is usually critical. Over the last two decades, solid phase extraction (SPE) has become the most powerful technique available for the sensitive and selective sample preparation prior to analytical chromatography. SPE extends the lifetime of chromatographic systems and improves qualitative and quantitative analysis. Different types of solid phase extraction (SPE) sorbents including $\mathrm{C} 18$ or $\mathrm{C} 8$ silica, ${ }^{14}$ polystyrene-divinylbenzene polymers, ${ }^{15}$ sol-gel organic-inorganic hybrid sorbents ${ }^{16}$ and various carbonaceous sorbents have been used, however it shows relatively low recovery for some relatively polar analytes. Carbon nanotubes (CNTs) it is a family type of nanomaterials made up entirely of carbon. ${ }^{17}$ This family contains Multi Walled Carbon Nanotubes (MWCNTs) which it is a new material has attracted special interest due to their high mechanical strength, young's modulus, thermal and electrical conductivity, and chemical stability. ${ }^{18}$ Several researches work has been reported on the use of MWCNTs as solid phase extraction (SPE) sorbents for the analysis of diverse types of pesticides. ${ }^{19-22}$

It has been recently reported that BPA may leach out into food and beverages samples from cans and plastic bottles which they were stored at two different temperatures at room temperature and direct sun light temperature. In the present work we use MWCNTs as minicolumn packing adsorbents for S solid phase extraction (SPE) of 
BPA from can. The BPA in the samples after extraction using solid phase extraction (SPE) was analyzed using HPLC with fluorescence detector.

\section{Materials and methods}

\section{Reagents}

BPA (purity 99.7\%) was obtained from Acros Organics (NJ). Standard stock solutions $(1000 \mu \mathrm{g} / \mathrm{mL})$ containing this compound were prepared by dissolving an appropriate amount of BPA in methanol. Working solution was prepared by an appropriate dilution of stock solutions with water. Methanol (chemical purity 100\%) was purchased from Scharalace Chemi SA, Barcelona, Spain. Sodium hydroxide ( $\geq 98 \%)$ and hydrochloric acid $(35 \%)$ were guarantee grade reagents (Beijing Chemicals Corporation, Beijing, China). MWNTs with an average external diameter of $30-60 \mathrm{~nm}$ were kindly provided by Tsinghua-Nafine Nano-Powder Commercialization Engineering Center.

\section{Apparatus}

The mini column $(6.0 \times 1.0 \mathrm{~cm}$ i.d. $)$, employed for packing the MWCNTs was made of polyethylene containing glass wool placed at both ends of mini column aiming to prevent sorbent losses during the system operation.

\section{Solid-phase extraction mini column}

A MWCNTs-packed mini column was prepared by modifying $0.5 \mathrm{~g}$ of MWCNTs was packed into the mini column. The $20 \mu \mathrm{g}$ polypropylene upper and lower frits remained at each end of the column to hold the MWCNTs packing in place. Prior to use, the entire SPE assembly was carefully washed with sufficient methanol.

\section{Instrumentation}

HPLC consisted of a high-pressure gradient pump (modelL-7100, Merck), a column thermostat, a six-port injection valve equipped with a $100 \mu \mathrm{L}$ injection loop was used, eluent used is methanol/water (60/40), was used as eluent, column size was C8 (150mmx4.6mm, $5 \mu \mathrm{m})$, and the extract volume was $50 \mu 1$. A fluorescence detector (model 1080, Merck) set at 275/305nm. Peaks were integrated using the McDacq software (Leonberg, Germany). Data given in this work were obtained in a time period of 2 months by applying different HPLC methods. A 744-pH Meter Metrohm (made in Switzerland) was used for $\mathrm{pH}$ measurement. Millipore SAS 67120 Molsheim system for deionized water.

Table I Analytical Data

\begin{tabular}{llll}
\hline Product & Sample Amount & Standard Addition Correlation Coefficient $\mathbf{R}^{2}$ & LOD (S/N=3) \\
\hline Beverages & & & $0.3 \mathrm{ng} / \mathrm{mL}$ \\
Cola drink & $20.0 \mathrm{~mL}$ & 0.9956 & $0.1 \mathrm{ng} / \mathrm{mL}$ \\
Orange soft drink & $15.0 \mathrm{~mL}$ & 0.9959 & $0.1 \mathrm{ng} / \mathrm{mL}$ \\
Lemon soft drink & $15.0 \mathrm{~mL}$ & 0.9999 & $2.9 \mathrm{ng} / \mathrm{g}$ \\
Vegetables & & & $1.9 \mathrm{ng} / \mathrm{g}$ \\
Corn & $1.0 \mathrm{~g}$ & 0.9949 & $1.3 \mathrm{ng} / \mathrm{g}$ \\
Crushed tomatoes & $1.0 \mathrm{~g}$ & 0.9906 & $5.5 \mathrm{ng} / \mathrm{g}$ \\
Fruits & $1.0 \mathrm{~g}$ & 0.9958 & $0.4 \mathrm{ng} / \mathrm{g}$ \\
Pineapple light & $1.0 \mathrm{~g}$ & 0.9942 & $0.2 \mathrm{ng} / \mathrm{g}$ \\
Mango & $10.0 \mathrm{~g}$ & 0.9989 & \\
Fat-Containing Products & $10.0 \mathrm{~g}$ & 0.9939 & \\
Tuna & &
\end{tabular}

Table 2 Determination and recoveries of BPA spiked canned food samples

\begin{tabular}{llll}
\hline Product & Added $(\mathbf{n g} / \mathbf{~ m l})$ & Found $(\mathbf{n g} / \mathbf{m l})$ & Recovery $(\%)$ \\
\hline Beverages & & & \\
\hline Cola drink & 10 & 9.35 & $93.5 \pm 4.9$ \\
Orange soft drink & 10 & 9.02 & $90.2 \pm 2.0$ \\
Lemon soft drink & 10 & 9.45 & $94.5 \pm 3.5$ \\
Vegetables & & 9.23 & $92.3 \pm 3.6$ \\
Corn & 10 & 9.66 & $96.6 \pm 8.2$ \\
Crushed tomatoes & 10 & 10.1 & $101.0 \pm 10.4$ \\
Fruits & 10 & 9.92 & $99.2 \pm 9.9$ \\
Pineapple light & 10 & & \\
Mango & 10 & 9.64 & $96.4 \pm 8.1$ \\
Fat-Containing Products & 10 & 10.2 & $102.0 \pm 10.6$ \\
Tuna & &
\end{tabular}

Table 3 BPA Concentrations in Canned Beverages,Vegetables, Fruits and Fat containing products Obtained by rounding standard deviation date calculated from four determination

\begin{tabular}{|c|c|c|c|c|c|c|c|}
\hline Product & $\begin{array}{l}\text { Country of } \\
\text { Origin }\end{array}$ & Content & $\begin{array}{l}\text { Amount of } \\
\text { Solid (g) }\end{array}$ & $\begin{array}{l}\text { Date of } \\
\text { Starge }\end{array}$ & $\begin{array}{l}\text { Date of } \\
\text { Analysis }\end{array}$ & $\begin{array}{l}\text { Conc. of Samples } \\
\text { Stored at Room Temp. } \\
\text { BPA } \pm \text { SD (ng/g) }\end{array}$ & $\begin{array}{l}\text { Conc. of Samples } \\
\text { Exposed to Sunlight } \\
\text { BPA士SD (ng/g) }\end{array}$ \\
\hline \multicolumn{8}{|l|}{ Beverages } \\
\hline Cola drink & Sudan & $300 \mathrm{~mL}$ & - & Apr-14 & Jun-I4 & $0.8 \pm 0.1$ & $2.1 \pm 0.1$ \\
\hline Orange soft drink & Sudan & $300 \mathrm{~mL}$ & - & Apr-14 & Jun-I4 & $0.4 \pm 0.1$ & $1.8 \pm 0.1$ \\
\hline Lemon soft drink & Sudan & $300 \mathrm{~mL}$ & - & Apr-14 & Jun-I4 & $0.3 \pm 0.0$ & $1.5 \pm 0.0$ \\
\hline
\end{tabular}


Table Continued...

\begin{tabular}{|c|c|c|c|c|c|c|c|}
\hline Product & $\begin{array}{l}\text { Country of } \\
\text { Origin }\end{array}$ & Content & $\begin{array}{l}\text { Amount of } \\
\text { Solid (g) }\end{array}$ & $\begin{array}{l}\text { Date of } \\
\text { Starge }\end{array}$ & $\begin{array}{l}\text { Date of } \\
\text { Analysis }\end{array}$ & $\begin{array}{l}\text { Conc. of Samples } \\
\text { Stored at Room Temp. } \\
\text { BPA } \pm \text { SD (ng/g) }\end{array}$ & $\begin{array}{l}\text { Conc. of Samples } \\
\text { Exposed to Sunlight } \\
\text { BPA } \pm \text { SD (ng/g) }\end{array}$ \\
\hline \multicolumn{8}{|l|}{ Vegetables } \\
\hline Corn & Egypt & $300 \mathrm{~g}$ & 280 & Apr-14 & Jun-I4 & $38 \pm 3.1$ & $43 \pm 3.5$ \\
\hline Crushed tomatoes & Sudan & $400 \mathrm{~g}$ & - & Apr-I4 & Jun-14 & $20 \pm 2.9$ & $30 \pm 2.0$ \\
\hline \multicolumn{8}{|l|}{ Fruits } \\
\hline Pineapple light & Sudan & $500 \mathrm{~g}$ & 350 & Apr-14 & Jun-I4 & $6.0 \pm 2.1$ & $8.0 \pm 3.0$ \\
\hline Mango & Sudan & $400 \mathrm{~g}$ & 250 & Apr-I4 & Jun-I4 & $24 \pm 4.0$ & $38 \pm 3.5$ \\
\hline \multicolumn{8}{|c|}{ Fat-Containing Products } \\
\hline Tuna & Sudan & $200 \mathrm{~g}$ & 150 & Apr-14 & Jun-I4 & $45 \pm 6.5$ & $55 \pm 7.1$ \\
\hline Sardines & Sudan & $200 \mathrm{~g}$ & 100 & Apr-14 & Jun-I4 & $2.1 \pm 0.3$ & $3.0 \pm 0.4$ \\
\hline
\end{tabular}

Table 4 Comparison of the published methods with the proposed method in this work

\begin{tabular}{|c|c|c|c|c|c|c|}
\hline & $\begin{array}{l}\text { Detection } \\
\text { Method }\end{array}$ & $\begin{array}{l}\text { Extraction } \\
\text { Method }\end{array}$ & & $\begin{array}{l}\text { Beverages BPA } \\
\text { Levels }\end{array}$ & $\begin{array}{l}\text { Canned Vegetables } \\
\text { BPA Levels }\end{array}$ & \\
\hline Food additive,20II & G C-MS & DLLME & $5.0 \mathrm{ng} / \mathrm{l}$ & $0.03-4.7 \mu g / I$ & - & \\
\hline Food control,2013 & GC-MS & DLLME & $0.3 \mu \mathrm{g} / \mathrm{kg}$ & - & $3.0 \mu \mathrm{g} / \mathrm{kg}$ & $3.4 \mu \mathrm{g} / \mathrm{kg}$ \\
\hline This work & HPLC-FL & SPE & $5.50 .1 \mathrm{ng} / \mathrm{ml} \mathrm{ng/g}$ & $0.3-2.1 \mathrm{ng} / \mathrm{ml}$ & $20-43 n g / g$ & $6.0-38 \mathrm{ng} / \mathrm{g}$ \\
\hline
\end{tabular}

\section{Evaluation of MWCNTs as SPE sorbents}

To evaluate the analytical potential of MWCNTs as solid phase extraction (SPE), BPA were adopted as model compound. The effects of different parameters, such as the sample volume, the eluent volume, and the $\mathrm{pH}$ of sample solution, on the recoveries were carefully investigated.

\section{Analysis of samples}

From April to June 2014 soft drinks bottles and canned food samples were purchased from Khartoum local supermarkets which they covered at least $80 \%$ of markets share of canned food products sold in Sudan. Some of the samples were stored at room temperature and the other exposed to direct sunlight for $<1$ month before analysis at June 2014. The samples distributes as follow: 6 samples of beverages bottles (cola drink, orange soft drink, lemon soft drink) 3 samples stored at room temperature and 3 samples exposed to direct sun light, 4 samples of canned vegetables (corn, crushed tomatoes) ,4 samples of canned fruits (pineapple, mango), 4 samples of canned fat containing-products (tuna, sardine), 2 samples of each kind of canned food were stored at room temperature and the other 2 samples were exposed to direct sun light.

\section{Sample preparation}

Beverages After the beverages had been degassed in an ultrasonic bath, an aliquot of either 15.0 or $20.0 \mathrm{~mL}$ was diluted $1: 1$ with buffer $\left(\mathrm{K}_{2} \mathrm{HPO}_{4} / \mathrm{NaOH}\right)$. If necessary, $\mathrm{pH}$ values were adjusted to 7.0 by adding a standardization buffer which it was prepared by adding $29.1 \mathrm{~mL}$ of 0.1 molar $\mathrm{NaOH}$ to $50 \mathrm{~mL}$ of $0.1 \mathrm{M}$ of dipotassium phosphate. The sample was applied to the mini column after the column had been washed with $5 \mathrm{~mL}$ of methanol/water (10/90, v/v), BPA was eluted with $2.5 \mathrm{~mL}$ of methanol/water $(70: 30, \mathrm{v} / \mathrm{v})$. The eluate was collected in a $5 \mathrm{~mL}$ measuring flask. This was filled to the ring mark with methanol/water $(70: 30, \mathrm{v} / \mathrm{v})$. An aliquot of $100 \mu \mathrm{L}$ was injected into HLPC.

Fruits and vegetables In the case of fruits and vegetables the whole content of the can only the solid portion was homogenized with UltraTurrax mixer. One gram of the homogenized sample was mixed with $2 \mathrm{~mL}$ of methanol in a $15 \mathrm{~mL}$ polypropylene centrifuge tube. After $1 \mathrm{~min}$ of shaking; centrifuging was carried out at $2800 \mathrm{~g}$ for $5 \mathrm{~min}$. The supernatant liquid was removed with a Pasteur pipet, and the solid residue was extracted for a second time with $1 \mathrm{~mL}$ of methanol. The combined supernatants were filtered through a glass microfiber filter $\mathrm{GF} / \mathrm{F}$. Then, the sample had been loaded to the mini column, the mini column had been washed with $5 \mathrm{~mL}$ of methanol/water $(10: 90 \mathrm{v} / \mathrm{v})$, after that BPA was eluted with $4 \mathrm{ml}$ of methanol/water $(70: 30 \mathrm{v} / \mathrm{v})$. The eluate was collected in a $5 \mathrm{~mL}$ measuring flask, which was then filled to the ring mark with methanol/water $(70: 30 \mathrm{v} / \mathrm{v})$. An aliquot of 100 $\mu \mathrm{L}$ was injected into HPLC.

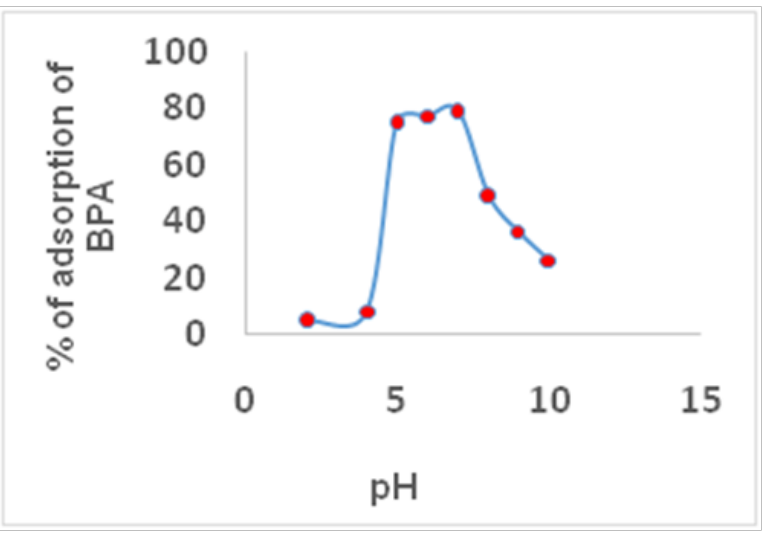

Figure I Effect of $\mathrm{pH}$ on adsorption of BPA.

Fat- Containing Food stuffs. For the analysis of tuna and sardines the liquid part was removed by sieving, and only the solid portion was homogenized. A $1 \mathrm{~g}$ aliquot of the homogenized sample (fish, 10g) was filled in a centrifuging tube. One milliliter of methanol and $1 \mathrm{~mL}$ of hexane (fish, $10 \mathrm{~mL}$ of methanol and $10 \mathrm{~mL}$ of hexane) were added, and the mixture was shaken for $1 \mathrm{~min}$. After centrifuging at $2800 \mathrm{~g}$ for $20 \mathrm{~min}$, the methanol phase was transferred into a centrifuging tube. The solid residue and hexane phase were extracted for a second time by adding a fresh $1 \mathrm{~mL}$ (fish, $10 \mathrm{~mL}$ ) portion of methanol. The combined methanol extracts were filtered through a glass microfiber filter GF/F. The filtrate was evaporated under a constant steam of nitrogen to approximately $2 \mathrm{~mL}$, diluted 1:10 with water, and purified as described above. An aliquot of $100 \mu \mathrm{L}$ was injected into HPLC.

Standard Addition For each food matrix the samples were analyzed as described above. The amounts of BPA in samples were determined in preliminary experiments. The addition of 10, 20 and 30ng of BPA $(100,200$ AND $300 \mu \mathrm{L}$ of a $100 \mathrm{ng} / \mathrm{mL}$ BPA standard solution in methanol) to the sample aliquot used proved to be appropriate. Peak areas were plotted against the amount of analyte added. The recovery 
was determined by dividing the slope of the linear regression line for the standard addition by the slope of the linear regression line of BPA standard solutions.

\section{Results and discussion}

\section{Effect of sample pH on adsorption}

The adsorption of BPA on MWCNTs depends on $\mathrm{pH}$ value. For the extraction of BPA, however, the $\mathrm{pH}$ of the sample solutions had no effect on the recoveries of bisphenol $\mathrm{A}$ in range of $\mathrm{pH} 2-4$, although a dramatic decrease in recoveries of BPA was observed due to deprotonation of hydroxyl of the phenol. The highest recovery $(\%)$ was obtained at $\mathrm{pH} 7$ as shown in Figure 1, therefore was chosen as the optimum $\mathrm{pH}$ to prepare sample solutions.

\section{Effect of eluent concentration and volume}

The eluent concentration is one of the most important parameters of desorption of BPA from the mini-column. It was found that methanol was an effective eluent for BPA analyte ${ }^{23,24}$ and therefore, it was accepted as an eluent. To find the required volume of methanol to elute the analyte from the mini column, eluent volumes up to $10 \mathrm{~mL}$ were investigated. The experimental results indicated the quantitative recoveries $(95 \%)$ could be achieved when the volume of methanol was in the range $2-10 \mathrm{~mL}$. Because application of a smaller volume of eluent contributes to obtaining a higher pre-concentration factor, $2.5 \mathrm{~mL}$ of methanol was adopted as the eluent throughout the experiments

\section{Effect of flow rate of sample solution}

The flow rate of sample solutions affects the retention of BPA on the adsorbent an duration of analysis. Therefore, the effect of flow rate of sample solutions on the desorption of BPA was examined under the optimum $\mathrm{pH}$ condition according to recommended procedure. It was found that flow rates up to $8 \mathrm{~mL} / \mathrm{min}$ (the maximum flow rate of our vacuum pump) for sample solution loading on the cartridge had no effect on the recoveries of the analyte. Therefore, $8 \mathrm{~mL} / \mathrm{min}$ was chosen as the flow rate of sample solutions.

\section{Effect of volume of the sample solution on the recoveries of BPA}

In order to explore the possibility of enriching low concentrations of analytes from large volumes, the effect of sample volume on the retention of BPA was also investigated. For this purpose, 700, 750, 800,850 , and $1000 \mathrm{~mL}$ of sample solutions containing $1.0 \mu \mathrm{g}$ of BPA were passed through the mini column with optimum flow rate. It was found that quantitative recovery $(>95 \%)$ of BPA was obtained for the sample volume up to $750 \mathrm{~mL}$. above $750 \mathrm{~mL}$ the recovery for BPA decreased slightly. In this experiment, $750 \mathrm{ml}$ of sample solution was adopted for the pre-concentration of BPA from food samples.

\section{Linearity of calibration curves and correlation coefficients}

For HPLC method the 18 calibration curve obtained by injecting BPA standard solutions range from 0.2 to $50.0 \mathrm{ng} / \mathrm{mL}$, good correlation coefficients ranged from 0.9906-0.9999 were obtained and Limit of detections (LODs) depending on the sample amount and HPLC method as well as the food matrix were in range from $0.1 \mathrm{ng} / \mathrm{Ml}$ to $5.5 \mathrm{ng} / \mathrm{g}$ all these results summarized in Table 1 .

\section{Analytical performance of the method}

The analytical performance of the whole analysis method was assessed by applying the standard addition method. The precision of the method applied, evaluated as the RSD, obtained in Table 2. Recovery tests were carried out with standard BPA, spiked canned food samples and the results are also presented in Table 2.

\section{BPA levels in canned foodstuffs.}

BPA levels found in canned foodstuffs are given in Table 3. Traces of BPA were detected in all samples, which the canned food products stored at room temperature and the same products exposed to direct sunlight for $<1$ month. Very low BPA levels of the beverages at room temperature obtained which they were ranging from $0.3 \mathrm{ng} / \mathrm{mL}$ to $0.8 \mathrm{ng} / \mathrm{mL}$. On the other hand, the soft drinks which they were exposed to direct sun light which the temperature was $<400 \mathrm{C}$ the levels of BPA was higher ranging from $1.5 \mathrm{ng} / \mathrm{mL}$ to $2.1 \mathrm{ng} / \mathrm{mL}$.

In the case of canned vegetables BPA concentrations were determined in solid portions, which are the parts of the can content actually consumed. In corn, BPA concentration was found to be $43 \mathrm{ng} / \mathrm{g}$ of solid portion when it was exposed to direct sun light but at the room temperature it was found to be $38 \mathrm{ng} / \mathrm{g}$, which is in agreement with previously reported data ranging from 18.4 to $95.3 \mathrm{ng} / \mathrm{g} .{ }^{25} \mathrm{In}$ crushed tomatoes BPA concentration, determined by analyzing the whole content of the can, was 20ng/g at room temperature and more concentrate when it was exposed to direct sun light which it was $30 \mathrm{ng} / \mathrm{g}$, which is consistent with the amount of BPA reported in the literature ${ }^{26,27}(<10-21 \mathrm{ng} / \mathrm{g})$.

Most canned fruits exhibited BPA levels at room temperature in the range from $6.0 \mathrm{ng} / \mathrm{g}$ for the light pineapple to $24.0 \mathrm{ng} / \mathrm{g}$ for mango, we obtained that the levels of BPA higher when they were exposed to direct sun light the found to be $8.0 \mathrm{ng} / \mathrm{g}$ for pineapple and $38.0 \mathrm{ng} / \mathrm{g}$, and this is corresponds to the data published by Thomson et al. ${ }^{28} \mathrm{In}$ fat-containing ready to eat products BPA levels at room temperature were $45 \mathrm{ng} / \mathrm{g}$ for tuna and $2.1 \mathrm{ng} / \mathrm{g}$ for sardine, The BPA concentration in the solid portion of tuna can when it was exposoed to direct sun light $55 \mathrm{ng} / \mathrm{g}$ and $3.0 \mathrm{ng} / \mathrm{g}$ for sardine which obviously higher than that stored at room temperature. The above results showed that the concentration of BPA in all samples exposed to direct sunlight is higher than samples that stored at room temperature. Also, MWCNTs were at least as effective as $\mathrm{C} 18$ for the solid phase extraction of BPA, but they were more effective. The reason that the MWNTs have a stronger interaction with BPA perhaps is that the hexagonal arrays of carbon atoms in graphene sheets in their structures may have a strong interaction with the benzene rings of BPA.

\section{Comparison study}

Table 4, compares the characteristic data of present method with those reported in literatures). ${ }^{29,30}$ Generally, The BPA levels obtained in the two reported work and this work was approximate to each other. We obtained that in beverages the levels of BPA is higher in the reported than our work but in the canned vegetables and fruits is much higher than in this work and this exactly due to higher temperture that canned exposed to when they were stored in direct sun light.

\section{Conclusion}

A simple and reliable method was developed for solid phase extraction (SPE) of BPA in several canned food products by using a MWCNTs packed mini column. The results obtained canned food products. For the more polar analytes, BPA, MWCNTs as solid phase extraction (SPE) adsorbents are more powerful than $\mathrm{C} 18$, because they possess a higher capability to extract BPA from larger volume of sample solutions. That the analytes retained on MWCNTs can be easily desorbed and no carryover is observed in the next analysis is another advantage of present method. In summary, we have 
preliminarily demonstrated that as promising sorbents, MWNTs have great potential for solid phase extraction of BPA.

It should mention that the samples of canned food products were collected in April 2014 one is stored at room temperature and the other same products exposed to direct sunlight before analysis in June 2014. We found that the concentration of BPA in canned food products is low in general, the average BPA level in all products in two situations was $0.8 \mu \mathrm{g} / \mathrm{g}$. The fact that the canned food products stored at room temperature had lower levels of BPA demonstrate that migration of BPA from can coatings into the food is extremely slow and is negligible. But, the canned food products which exposed to direct sunlight for $>1$ month had relatively high levels of BPA due to the fast migration from their can coatings into food during the can sterilization process.

Variation of BPA levels in different canned food products (0.14$4.71 \mu \mathrm{g} / \mathrm{g}$ ) in this analysis is due to careless exposure of products to heat (sunlight) during storage and transportation. Also, it could be due to differences in can coatings (type, amount, etc.) and can sterilization condition (temperature - duration) used by different canned food products companies. We found in our analysis that if someone eating in just one meal with at least one canned food product, their levels of BPA are as much as those that have been shown to cause health effects So, we have some recommendations to avoid the dangerous effects of BPA, Cook your food fresh, Buy in glass bottles. But even they may have trace amounts of BPA we have ways to beat BPA from canned food. Don't use canned baby formula, don't eat canned food if you are pregnant, Also, Buy in bottles, not cans. Many products, like crushed tomato, are available in bottles as well as cans, Start cooking instead of just heating. The fact that $17 \%$ of the Sudanese dieses comes out of cans is just a scandal when we are surrounded by fresh food. Cook it from scratch and avoid the problem altogether.

\section{Acknowledgments}

None.

\section{Conflicts of Interset}

None.

\section{References}

1. Fasano E, Esposito F, Scognamiglio G, et al. Bisphenol A contamination in soft drinks as a risk for children's health in Italy. Food Addit Contam Part A Chem Anal Control Expo Risk Assess. 2015;32(7):1200-1207.

2. Hartle JC, Navas-Acien A, Lawrence RS. The consumption of canned food and beverages and urinary Bisphenol A concentrations in NHANES 2003-2008. Environ Res. 2016;150:375-382.

3. Hadiani MR, Farhangi R, Soleimani H, et al. Evaluation of heavy metals contamination in Iranian foodstuffs: canned tomato paste and tomato sauce (ketchup). Food Addit Contam Part B Surveill. 2014;7(1):74-78.

4. Geens T, Apelbaum TZ, Goeyens L, et al. Intake of bisphenol A from canned beverages and foods on the Belgian market. Food Addit Contam Part A Chem Anal Control Expo Risk Assess. 2010;27(11):1627-1637.

5. Sungur S, Koroğlu M, Özkan A. Determinatıon of bisphenol a migrating from canned food and beverages in markets. Food Chem. 2014;142:8791.

6. Maamar MB, Lesne L, Desdoits-Lethimonier C, et al. An investigation of the endocrine-disruptive effects of bisphenol a in human and rat fetal testes. PLoS One. 2015;10(2):117226-1172229.

7. Li L, Wang Q, Zhang Y, et al. The molecular mechanism of bisphenol A (BPA) as an endocrine disruptor by interacting with nuclear receptors: insights from molecular dynamics (MD) simulations. PLoSOne. 2015;10(3):12029-12033.
8. Iqbal K, Tran DA, Li AX, et al. Deleterious effects of endocrine disruptors are corrected in the mammalian germline by epigenome reprogramming. Genome Biol. 2015;16:59-63.

9. Abdel-Wahab WM. Thymoquinone attenuates toxicity and oxidative stress induced by bisphenol A in liver of male rats. Pak J Biol Sc. 2014;17(11):1152-1160.

10. Nachman RM, Fox SD, Golden WC, et al. Urinary free bisphenol a and bisphenol A-glucuronide concentrations in newborns. $J$ Pediatr. 2013;162(4):870-872.

11. Dang A, Sieng M, Pesek JJ, et al. Determination of bisphenol A in receipts and carbon paper by HPLC-UV. Journal of Liquid Chromatography and Related Technologies. 2015;38(4):438-442.

12. Ballesteros-Gómez A, Rubio S, Pérez-Bendito D. Analytical methods for the determination of bisphenol $\mathrm{A}$ in food. $J$ Chromatogr $A$. 2009;1216(3):449-469.

13. Chen XP, Fan RJ, Zhang F, et al. Chromatographic peak reconstruction algorithm to improve qualitative and quantitative analysis of trace pesticide residues. Rapid communication in mass spectrometry. 2006;230(4):2655-2663

14. Kulsing C, Yang Y, Sepehrifar R, et al. Investigations into the separation behaviour of perfluorinated $\mathrm{C} 8$ and undecanoic acid modified silica hydride stationary phases. Anal Chim Acta. 2015;916:102-111.

15. Yamauchi Y, Taoka M, Nobe Y, et al. Chromatogr A. Denaturing reversed phase liquid chromatographic separation of non-coding ribonucleic acids on macro-porous polystyrene-divinylbenzene resins. J Chromatogr A. 2013;1312:87-2.

16. Omar MMA, Wan Ibrahim WA, Elbashir AA. Sol-gel hybrid methyl trimethoxysilane-tetraethoxysilane as a new dispersive solid-phase extraction material for acrylamide determination in food with direct gas chromatography-mass spectrometry analysis. Food Chemistry. 2014;158:302-309.

17. Ding J, Gao Q, Li XS, et al. Magnetic solid-phase extraction based on magnetic carbon nanotube for the determination of estrogens in milk. Journal of Separation Science. 2011;34(18):2498-2504.

18. Camilli L, Scarselli M, Gobbo SD, et al. Structural, electronic and photovoltaic characterization of multiwalled carbon nanotubes grown directly on stainless steel. Beilstein J Nanotechnol. 2012;3:360-367.

19. Dong M, Si W, Jiang K, et al. Multi-walled carbon nanotubes as solidphase extraction sorbents for simultaneous determination of type A trichothecenes in maize, wheat and rice by ultra-high performance liquid chromatography-tandem mass spectrometry. J Chromatogr A. 2015;1423:177-182.

20. Herrera-Herrera AV, Hernández-Borges J, Afonso MM, et al. Comparison between magnetic and non magnetic multi-walled carbon nanotubesdispersive solid-phase extraction combined with ultra-high performance liquid chromatography for the determination of sulfonamide antibiotics in water samples. Talanta. 2013;116:695-703.

21. Hadjmohammadi MR, Peyrovi M, Biparva P. Comparison of C18 silica and multiwalled carbon nanotubes as the adsorbents for the solid-phase extraction of Chlorpyrifos and Phosalone in water samples using HPLC. J Sep Sci. 2010;33(8):1044-1051.

22. Herrero-Latorre C, Barciela-García J, García-Martín S,et al. Magnetic solid-phase extraction using carbon nanotubes as sorbents: A review. Analytica Chimica Acta. 2015;892:10-26.

23. Zhou Q, Ding Y, Xiao J. Simultaneous Determination of Cyanazine, Chlorotoluron and Chlorbenzuron in Environmental Water Samples with SPE Multiwalled Carbon Nanotubes and LC. Chromatographia. 2017:65(1-2):25-30.

24. Jiao Y, Ding L, Fu S, et al. Determination of bisphenol A, bisphenol $\mathrm{F}$ and their diglycidyl ethers in environmental water by solid phase extraction using magnetic multiwalled carbon nanotubes followed by GC-MS/MS. Analytical Methods. 2012;4(1):291-298. 
25. Yoshida T, Horie M, Hoshino Y, et al. Determination of bisphenool A in canned vegetables and fruit by HPLC. Food Addit Contam. 2001;18(1):69-73.

26. Thomson BM, Grounds PR. Bisphenol A in canned foods in New Zealand: an exposure assessment. Food Addit Contam. 2005;22(1):6569.

27. Biles JE, McNeal TP, Begley TH. Determination of bisphenol A migrating from epoxy can coatings to infant formula liquid concentrates. Journal of Agricultural and Food Chemistry. 2017;45(12):4697-4700.

28. Thompson BJ, Mathieu J, Sung HH, et al. Tumor suppressor properties of the ESCRT-II complex component Vps25 in Drosophila. Dev Cell. 2005;9(5):712-718
29. Cunha SC, Fernandes JO. Assessment of bisphenol A and bisphenol B in canned vegetables and fruits by gas chromatography-mass spectrometry after QuEChERS and dispersive liquid-liquid microextraction. 2013;33:549-555.

30. Cunha SC, Almeida C, Mendes E. Simultaneous determination of bisphenol $\mathrm{A}$ and bisphenol $\mathrm{B}$ in beverages and powdered infant formula by dispersive liquid-liquid micro-extraction and heart-cutting multidimensional gas chromatography-mass spectrometry. Food Additive and Cont. 2011;28:513-526. 